\title{
Potential Defensive Effect of Royal Jelly Compared to Cyclophosphamide Induced Hemotoxicity
}

\author{
Syeda Hina Kausar ${ }^{1 *}$, Vitthal Ram More ${ }^{2}$ \\ ${ }^{1}$ PhD Scholar, Department of Zoology, GASCA, Dr. BAMU University, Aurangabad, (M.S.) India \\ ${ }^{2}$ Associate Professor, Department of Zoology, GASCA, Dr. BAMU University, Aurangabad, (M.S.) India
}

*Address for Correspondence: Ms. Syeda Hina Kausar, PhD Scholar, Department of Zoology, GASCA, Dr. BAMU University, Aurangabad, (M.S.) India

E-mail: hina33113@gmail.com

Received: 06 Oct 2018/ Revised: 16 Feb 2019/ Accepted: 08 Apr 2019

\begin{abstract}
Background: A major side effect of cyclophosphamide (CPA) during chemotherapy is hemotoxicity. Use of natural products like royal jelly reduced the adverse effect of a drug. A current study was an effort to find out the potential defensive effects of royal jelly against hemotoxicity induced by cyclophosphamide in male albino mice.

Methods: Male Swiss albino mice of $20 \pm 5$ gms were unevenly divided into six groups; G1: normal control group $0.9 \%$ saline solution I.P. weekly, G2: royal jelly ( $100 \mathrm{mg} / \mathrm{kg} / \mathrm{d}) \mathrm{CMC}$ suspended administered by orally, G3: cyclophosphamide (50 mg/kg/week) was injected intra-peritoneally, G4: I.P. cyclophosphamide $(50 \mathrm{mg} / \mathrm{kg} /$ week) along with royal jelly (100 mg/kg/d), G5: I.P. cyclophosphamide (50 mg/kg/week) with royal jelly $(250 \mathrm{mg} / \mathrm{kg} / \mathrm{d}), \mathrm{G6}$ : I.P. cyclophosphamide (50 mg/kg/week) and royal jelly $(500 \mathrm{mg} / \mathrm{kg} / \mathrm{d})$. The experiment lasted for 12 weeks. The measurement of hematological parameters CBC was performed using automated hematology system. Mean \pm SEM one way ANOVA followed by Tukey's test were performed to find out the significant difference between groups.

Results: Cyclophosphamide treated mice exhibit leucopenia, erythrocytopenia, thrombocytopenia and the significant reduction in hemoglobin $(\mathrm{Hb})$, packed cell volume (PCV), mean corpuscular volume (MCV), mean corpuscular hemoglobin (MCH), and mean corpuscular hemoglobin concentration $(\mathrm{MCHC})$ as compared to control group. The administration of royal jelly to CPA treated mice, according to the present experimental plan significantly improves the alterations induced in haemogram.

Conclusion: It was suggested that royal jelly ameliorate cyclophosphamide-induced hematological alterations, thus it might be used as a dietary protective natural remedy during the chemotherapy.
\end{abstract}

Key-words: Cyclophosphamide, Erythrocytopenia, Haemotoxicity, Leucopenia, Royal jelly, Swiss albino mice, Thrombocytopenia

\section{INTRODUCTION}

Since the late 1950s the alkylating agent CPA was in general used in chemotherapy because of its curative quality and wide-range of activities against a wide range of cancers ${ }^{[1]}$. The most common use of cyclophosphamide is in the treatment of different types of hematological and solid malignancies, autoimmune disorders like rheumatoid arthritis, systemic lupus erythematosus, and multiple sclerosis and other medical conditions $^{[2-5]}$.

\section{How to cite this article}

Kausar SH, More VR. Potential Defensive Effect of Royal Jelly Compared to Cyclophosphamide Induced Hemotoxicity. SSR Inst. Int. J. Life Sci., 2019; 5(3): 2269-2277.

Access this article online
https://iijls.com/

However, the clinical use of this drug is limited due to the comprehensive side effects and toxicities like nausea, vomiting, alopecia, bone marrow suppression, hepatotoxicity, nephrotoxicity, neurotoxicity, cardiotoxicity, immune-toxicity, mutagenicity, teratogenicity, and carcinogenicity ${ }^{[6-8]}$. The most harmful effect is genotoxicity related to DNA binding characteristics of CPA ${ }^{[9]}$.

CPA-induced nucleic acid damage causes DNA mutations that result in cytotoxicity, carcinogenicity and teratogenicity ${ }^{[3]}$. In normal tissues and organs, some toxicity like oxidative stress is stimulated by CPA because of the generation of free radicals ${ }^{[10]}$. So, the compound consisting antioxidant and cyto-protective properties may be beneficial if given with a CPA as a combined treatment regimen for the protection of normal cells and tissues against CPA-induced toxicities. 
Royal jelly was nothing but a natural milky material, secreted from the hypo-pharyngeal and mandibular glands of worker honeybees which were a complete food source for honeybee larvae ${ }^{[11]}$. Royal jelly containing varieties of nutritional components like proteins, lipids, carbohydrates, vitamins, and minerals ${ }^{[12]}$. It has a lot of properties such as anti-tumor and anti-inflammatory properties, anti-fatigue and hypotensive activity ${ }^{[13-15]}$, antioxidant activities [16], antibacterial effects and enhancement of immune activity. Due to these exclusive properties, Royal jelly has become very important for human beings. So, we considered the beneficial properties of Royal jelly against cyclophosphamide induced hemotoxicity in mice.

Blood is a connective tissue contains RBCs, WBCs, and platelets, which are suspended in a fluid medium; plasma. The main function of blood is to distribute vital materials such as nutrients and oxygen and carry away the waste products from the cells. Complete blood count (CBC) is routinely performed clinical laboratory test which is required to asses or diagnose health problem related to blood.

\section{MATERIALS AND METHODS}

Chemicals- The tested compound CPA were bought from Zydus Cadila, (G.Rem). Royal jelly was purchase from the apiculture farm of Hi-tech Natural product (India) Ltd from colonies of Apis mellifera in the lyophilized form.

Food pallet was purchased from VRK Nutritional solution, Pune, Maharashtra (India). All other chemicals used in this experiment were of analytical grade from Merck (India) Ltd, Mumbai, India. The dose has been selected on the basis of previously published studies and by acute toxicological study.

Preparation of Royal jelly and Cyclophosphamide- At the proportion of $100 \mathrm{mg} / \mathrm{kg} / \mathrm{d} / \mathrm{mice}$ of Royal jelly was dissolved in 5\% CMC (carboxymethyl cellulose) suspension administered through an intra-gastric tube through the mouth ${ }^{[17]}$. While CPA was injected through intra-peritoneal rout at the proportion of $50 \mathrm{mg} / \mathrm{kg} / \mathrm{mice}$ by dissolving in distilled water for combine dose different proportions of Royal jelly as $100 \mathrm{mg} / \mathrm{kg}, 250 \mathrm{mg} / \mathrm{kg}$, and $500 \mathrm{mg} / \mathrm{kg}$ were suspended in CMC. The doses were weighed on SF-400 digital LCD balance.

Animals- Total of 36 Pathogen-free male Swiss albino mice with a weight of $20 \pm 5 \mathrm{~g}$ were obtained from the laboratory of Wockhardt Research Institute Aurangabad
M.S., India. The experimentation performed was in full compliance with the guidelines of the committee for the purpose of control and supervision of experiments on the animal (CPCSEA) Act of 2007 Govt. of India on animal welfare. The study protocol was approved by the Institutional Animal Ethics Committee (IAEC) of Y.B. Chavan College of Pharmacy, Aurangabad, and (MH) India (Ref. No. CPCSEA/IAEC/Pcology-53/2017-18/134).

Housing conditions- The mice were housed in standard polypropylene cages having a size of $32 \times 11 \mathrm{~cm}$ with stainless steel grill top mesh having facility for holding food palate and a water bottle. The bedding material of the cages was changed daily. Maximum of 6 mice housed per polypropylene cage. All mice were maintained under standard laboratory conditions $\left(25 \pm 1^{\circ} \mathrm{C}\right.$ temperature; $12: 12 \mathrm{~h}$ light/dark and $50-60 \%$ humidity) and isolated for 7 days prior to the start of the study. Standard rodent chow diet and water were provided ad libitum to the experimental animals.

Study Design and Plan- Total 36 adult male Swiss albino mice of 8 - 9 week age and with $20 \pm 5$ g weight were randomly allocated into 6 groups; each group consisting of 6 mice and the experiment lasted for 12 weeks. After an acclimatization period of one week (G1-G6):

G1: Normal Control Group (C): served as healthy control. Mice fed only with basal diet and water and were administered with $0.9 \%$ Normal saline $(10 \mathrm{ml} / \mathrm{kg} /$ week), for 12 weeks.

G2: Royal jelly group (Royal jelly): mice were administered with Royal jelly $(100 \mathrm{mg} / \mathrm{kg})$ CMC suspended orally everyday between $10 \mathrm{AM}$ to $11 \mathrm{AM}$ for each mouse for 12 weeks.

G3: Cyclophosphamide Group (CPA): was injected with CPA $50 \mathrm{mg} / \mathrm{kg} /$ week, for 12 weeks (once in a week) by the intra peritoneally.

G4: CPA and Low dose royal jelly Group (CPA+royal jelly1): were injected with CPA $(50 \mathrm{mg} / \mathrm{kg} /$ week) followed by royal jelly administered orally (100 $\mathrm{mg} / \mathrm{kg} /$ day) respectively, for 12 weeks.

G5: CPA and Medium dose royal jelly Group (CPA+ royal jelly2): mice were injected with CPA (50 $\mathrm{mg} / \mathrm{kg} / \mathrm{week})$ followed by royal jelly administered orally $(250$ $\mathrm{mg} / \mathrm{kg} /$ day) respectively for 12 weeks. 
G6: CPA and High dose royal jelly Group (CPA+ royal jelly3): mice were injected with CPA (50 mg/kg/week) followed by Royal jelly (500 mg/kg/day) respectively, for 12 weeks.

Collection of blood- After 12 weeks of exposure approximately $1 \mathrm{ml}$ of blood samples were obtained using mice bleeding tubes from retro-orbital sinus plexus in EDTA-containing tubes. All blood samples were labelled and immediately analyzed for a complete blood count.

Measurements of Hematological parameters- All hematological parameters like total erythrocyte count, total leukocyte count, total thrombocyte count, \% hemoglobin $(\mathrm{Hb}), \mathrm{PCV}$, the mean corpuscular values of $\mathrm{MCV}, \mathrm{MCH}$ and $\mathrm{MCHC}$ were analyzed using the automated hematology method with the "Hematology auto-analyzer Sysmex $\times 100$. The blood analyzer was periodically calibrated.

Statistical Analysis- All Values were expressed as means \pm SEM. Graph pad PRISM 6.01 for windows computer program was used for statistical analysis of the results. Data were analyzed using the one-way analysis of variance (ANOVA) followed by Tukey's post hoc test for multiple comparisons. The value of $* * * P<0.001$, $* * \mathrm{P}<0.01, * \mathrm{P}<0.05$ were considered to be statistically significant.

\section{RESULTS}

Effect of treatment of royal jelly (G2), cyclophosphamide (G3), and combined treatment of cyclophosphamide with royal jelly at a different proportions low dose (G4) (100 mg/kg), medium dose (G5) (250 mg/kg), and high dose (G6) (500 mg/kg) on male Swiss albino mice on hematological parameters were evaluated. All Groups from (G2 and G3) were compared with normal control (G1) group while combined treatment groups (G4-G6) were compared with cyclophosphamide (G3) group for the period of 12 weeks and obtained results are summarized in Table 1.

Table 1: Effect of Royal jelly on CPA-induced changes in Hematological parameters in Male albino mice

\begin{tabular}{|c|c|c|c|c|c|c|}
\hline $\begin{array}{l}\text { Groups } \\
\text { Parameters }\end{array}$ & $\begin{array}{l}\text { G1: } \\
\text { Cont. }\end{array}$ & $\begin{array}{c}\text { G2: } \\
\text { Royal jelly }\end{array}$ & $\begin{array}{l}\text { G3: } \\
\text { CPA }\end{array}$ & $\begin{array}{c}\text { G4: } \\
\text { Royal jelly }+ \text { CPA }\end{array}$ & $\begin{array}{c}\text { G5: } \\
\text { Royal } \\
\text { jelly }+ \text { +CPA }\end{array}$ & $\begin{array}{c}\text { G6: } \\
\text { Royal jelly }{ }_{3+} \text { CPA }\end{array}$ \\
\hline \multirow[t]{2}{*}{ WBCs $\left(10^{3} / \mu \mathrm{l}\right)$} & $5.46 \pm$ & $6.14 \pm$ & $1.49 \pm$ & $2.14 \pm$ & $3.84 \pm$ & $5.03 \pm$ \\
\hline & 0.38 & 0.54 & $0.44^{* * *}$ & 0.52 & $0.52+$ & $0.52+t$ \\
\hline \multirow[t]{2}{*}{ RBCs $\left(10^{6} / \mu \mathrm{l}\right)$} & 7.16 & $9.67 \pm$ & $2.34 \pm$ & $3.85 \pm$ & $5.43 \pm$ & $7.42 \pm$ \\
\hline & \pm 0.98 & $0.47^{*}$ & $0.64^{* * *}$ & 0.41 & $0.40+t$ & $0.50++\dagger$ \\
\hline \multirow[t]{2}{*}{$\operatorname{PLT}\left(10^{3} / \mu \mathrm{l}\right)$} & 277 & $398 \pm$ & $79 \pm$ & $175 \pm$ & $239 \pm$ & $310 \pm$ \\
\hline & \pm 36.01 & $49.88^{*}$ & $10.57^{* * *}$ & 8.70 & $19.65+t$ & $23.08++\dagger$ \\
\hline $\mathrm{Hb}$ & 10.46 & $12.69 \pm$ & $6.08 \pm$ & $6.87 \pm$ & $8.65 \pm$ & $10.23 \pm$ \\
\hline (g/dl) & \pm 0.65 & 0.78 & $0.70^{* * *}$ & 0.58 & $0.63+\dagger$ & $0.30++†$ \\
\hline PCV & 34.00 & $36.50 \pm$ & 19.28 & 21.17 & 26.47 & 32.16 \\
\hline (\%) & \pm 2.64 & 3.39 & $\pm 1.00^{* * *}$ & \pm 1.30 & $\pm 1.83^{\dagger}$ & $\pm 1.42+\dagger$ \\
\hline MCV & 50.17 & 62.17 & 18.17 & 21.83 & 34.67 & 50.33 \\
\hline (fl) & \pm 2.30 & $\pm 2.35^{*}$ & $\pm 1.01^{* * *}$ & \pm 3.20 & $\pm 2.29+\dagger$ & $\pm 3.14+†+$ \\
\hline
\end{tabular}




\begin{tabular}{ccccccc}
\hline MCH & 23.48 & 30.00 & 11.45 & 12.43 & 16.19 & 22.64 \\
(pg) & \pm 1.10 & $\pm 2.23^{*}$ & $\pm 1.31^{* *}$ & \pm 1.05 & $\pm 1.93^{\dagger}$ & $\pm 2.26{ }^{+\dagger}$ \\
$\mathrm{MCHC}$ & 33.50 & 42.83 & 16.83 & 19.17 & 27.33 & 32.62 \\
(g/dl) & \pm 1.96 & $\pm 3.38^{*}$ & $\pm 1.92^{* * *}$ & \pm 1.92 & $\pm 2.37+$ & $\pm 2.10^{+\dagger}$
\end{tabular}

$\mathrm{P}<0.05^{*}, \mathrm{P}<0.01^{* *}, \mathrm{P}<0.001^{* * *}$ vs. normal control group $\mathrm{P}<0.05+, \mathrm{P}<0.01++, \mathrm{P}<0.001++t v s$. CPA injected group

Total Leucocyte count- The current study demonstrated that the royal jelly treatment (G2) non-significantly increased the total leukocyte count compared to the control group (G1). However, a significant reduction $(P<0.001)$ in leukocyte count in cyclophosphamide injected mice (G3) was observed as compared with the control (G1). Similarly, there was a non-significant difference in the total leukocyte count was seen in CPA with a low dose (100 mg/kg) RJ group (G4) compared to CPA-injected mice of (G3).

Interestingly, the mice that injected with CPA along with medium $(250 \mathrm{mg} / \mathrm{kg})$ and high dose $(500 \mathrm{mg} / \mathrm{kg})$ of Royal jelly (G5 and $G 6)$ displayed a significant increase $(P<0.05$, $\mathrm{P}<0.01)$ in the total leukocyte count compared to CPAinjected group (G3).

Total Erythrocyte count- After experimental period of 12 weeks it was observed that mice of the royal jelly group (G2) exhibited significantly increased erythrocyte count $(P<0.05)$ contrast to control group (G1), whereas mice treated with a cyclophosphamide (G3) showed a significant decline $(P<0.001)$ in the total $R B C$ count as compared to control (G1). Mice of a combined treatment group such as $100 \mathrm{mg} / \mathrm{kg}$ of royal jelly with CPA (G4) were significantly similar to CPA injected group, while mice of the group royal jelly $250 \mathrm{mg} / \mathrm{kg}$ and $500 \mathrm{mg} / \mathrm{kg}$ with CPA ( $G 5$ and $G 6$ ) showed significant improvement in the total $R B C$ count $(P<0.01$ and $P<0.001)$ as compared with CPA injected (G3) group.

Total Thrombocyte count- After completion of 12 weeks, there was a significant rise $(P<0.05)$ for the thrombocyte count were observed in Royal jelly treated groups (G2) against normal control (G1) (Table 1). However significant decline $(P<0.001)$ were recorded in CPA injected mice (G3) contrast to the control (G1) group. The G4 (CPA with $100 \mathrm{mg} / \mathrm{kg}$ royal jelly) was significantly not different from CPA injected (G3) group. Though, on the other side, there was significant progress $(P<0.01$,
$\mathrm{P}<0.001)$ found in the platelet count of CPA with 250 $\mathrm{mg} / \mathrm{kg}$ and $500 \mathrm{mg} / \mathrm{kg}$ of Royal jelly group $(\mathrm{G} 5, \mathrm{G} 6)$ when compared with CPA injected (G3) group.

Percent $\mathbf{H b}$ concentration- (G2) in which Royal jelly given alone by gavages to all the animals showed the nonsignificant difference in terms of $\mathrm{Hb}$ concentration, compared with the control group (G1). Whereas Animals treated with the cyclophosphamide (G3) revealed a significant reduction in the level of $\mathrm{Hb} \quad(P<0.001)$ compared to the control (G1) group indicating its toxicity. CPA with Low dose Royal jelly (G4) group exhibited a non-significant difference against CPA (G3) group.

Effect of royal jelly on the toxicity induced by CPA revealed a significant improvement $(P<0.01, P<0.001)$ when CPA and Royal jelly gave in a medium (G5) and high doses (G6) compared with the CPA injected group (G3).

Hematological indices- At the termination of the experimental period PCV of the Royal jelly treatment group (G2), were non-significantly increased while the significant elevation $(P<0.05)$ in terms of $\mathrm{MCV}, \mathrm{MCH}$ and MCHC were recorded as compared to control (G1).A significant demotion $(P<0.001)$ in the $P C V, M C V$ and MCHC while the decline was $(P<0.01)$ in the $\mathrm{MCH}$ levels were observed in Cyclophosphamide injected mice group (G3) when compared with the control (G1) group.

Correspondingly, there was a non-significant elevation were found in all the indices in CPA with $100 \mathrm{mg} / \mathrm{kg}$ of Royal jelly (G4) compared with the CPA-injected mice of (G3) group, even though significantly increased levels $(\mathrm{P}<0.05)$ of $\mathrm{PCV}, \mathrm{MCH}$ and $\mathrm{MCHC}$ while $(\mathrm{P}<0.01)$ of $\mathrm{MCV}$ in (G5) group were observed as compared to (G3) group. Alike the mice that injected with CPA along with a Royal jelly at a proportion of $500 \mathrm{mg} / \mathrm{kg}$ (G6) showed a significant increase $(\mathrm{P}<0.01)$ in the $\mathrm{PCV}, \mathrm{MCH}$ and $\mathrm{MCHC}$ levels while improvement $(P<0.001)$ in $M C V$ were seen compared with CPA-injected mice (G3). 


\section{DISCUSSION}

Chemotherapeutic agents mostly killed rapidly dividing cells in the body, targeting cancer cells along with normal cells originating from the bone marrow. CPA is a cytotoxic alkylating agent forming reactive oxygen species (ROS), which reacts with DNA. Initially, in the liver the CPA was activated by microsomal oxidation system enzyme cytochrome P450 converting CPA into 4hydroxy CPA, a cytotoxic metabolite, and then 4- hydroxy CPA was further converted to some other cytotoxic metabolites as phosphoramide mustard and acrolein ${ }^{[18]}$. Phosphoramide mustard, the active metabolite of CPA forms DNA crosslink's which lead to DNA strand breaks and subsequently to chromosomal breaks. Acrolein, the other metabolite interfered with tissue antioxidant defense mechanism, through producing highly reactive oxygen free radicals that further react with DNA causing its damage ${ }^{[19]}$.

In the present study after a chronic administration of CPA for 12 weeks, a severe hemotoxicity had seen in CPA treated mice a contrast to the normal untreated mice. A noticeable decrease was detected in the $\mathrm{Hb}$ concentration, leukocytes count, erythrocyte count, thrombocyte count, mean volume of $\mathrm{PCV}, \mathrm{MCV}, \mathrm{MCH}$ and MCHC. Similar results were reported by Elshater et al. ${ }^{[20]}$; Bhattacharjee et al. ${ }^{[21]}$; and Duggina et al. ${ }^{[22]}$.

The results of the study demonstrated that 12 weeks of CPA treatment significantly decreased the total leukocyte count. This might be due to myelosuppression and oxidative stress during CPA treatment.

The main molecular mechanism of CPA was myelotoxicity. Active metabolites of CPA can interact with the cellular macromolecules such as proteins, membrane lipids, RNA, as well as DNA and render the cell incapable of replication and induce apoptosis ${ }^{[23]}$. One of its metabolite, namely acrolein, induces oxidative stress that leads to DNA damage of normal cells. Reactive oxygen species are toxic to bone marrow cells and probably can trigger apoptosis and affect cell cycle, causing anemia and a decrease in leukocyte count. Myelosuppression resulting in leucopenia and thrombocytopenia is a frequent and major complication of cancer chemotherapy. Shalit et al. ${ }^{[24]}$ observed that the total leukocyte count was decreased after exposure to cyclophosphamide administration. The decrease in WBC count recorded in the CPA-injected rats might be the consequence of the oxidative stress which induced lipid peroxidation and damage of blood cell membranes.

De Weerdt et al. [25] revealed CPA causes myelosuppression, affecting neutrophils and lymphocytes. According to Duggina et al. ${ }^{[22]}$ showed significantly decreased counts of neutrophils and lymphocytes in CPA treated rats as compared to control group. Fraiser et al. ${ }^{[26]}$ reported cyclophosphamide induced leucopenia and granulocytopenia which increases the patient's susceptibility to pathogenic bacteria or opportunistic microorganisms.

After 12 weeks of cyclophophamide treatment to mice, the thrombocytet count was significantly decreased compared to the control group. This might be due to CPA inhibiting bone marrow activity or could be due to decreased production of platelets ${ }^{[27]}$. CPA that produces a transient hemopoietic depression has been reported to cause a persistently low number of stem cells of bone marrow ${ }^{[28]}$.

Although cyclophosphamide is generally considered to be platelet-sparing, thrombocytopenia can also be a significant complication leading to an increased potential for bleeding episodes. Similar results were observed by Langford, revealed Bone marrow suppression is the main toxicity induced by CPA and in turn, decreased in platelets counts ${ }^{[29]}$.

The total erythrocyte count and $\mathrm{Hb} \%$ After 12 week of CPA treated mice were significantly decreased as compared to control. Similar results were reported by Ahmed et al. ${ }^{[30]}$. The previous results suggested that there was an etiological relationship between anemia and CPA treatment. This relation could be explained through different mechanisms, including the destruction of bone marrow cells or increased osmotic fragility of RBC. Thus, cap therapy might lead to anemia as a result of either suppression of the activity of hematopoietic tissues, impaired erythropoiesis, and accelerated RBCs destruction because of the altered RBCs membrane permeability, increased RBCs mechanical fragility, and/or defective iron metabolism.

Erythrocytes may undergo apoptosis-like suicidal death or eryptosis, which is characterized by cell membrane scrambling ${ }^{[31]}$. Despite the weak effect of acrolein on cytosolic $\mathrm{Ca}^{2+}$ activity, acrolein exposure leads to decrease of forward scatter reflecting a decrease of cell volume. Eryptotic erythrocyte shrinkage may result from activation of $\mathrm{Ca}^{2+}$ sensitive $\mathrm{K}^{+}$channels with subsequent 
$\mathrm{K}^{+}$exit, cell membrane hyperpolarization, $\mathrm{Cl}$-exit and thus cellular loss of $\mathrm{KCl}$ with osmotically obliged water [32] whether or not those channels are activated following exposure to acrolein, remains to be shown.

The $\mathrm{Ca}^{2+}$ sensitivity of the erythrocyte cell membrane scrambling was enhanced by ceramide. Acrolein treatment indeed resulted in an increase in ceramide formation. Thus, acrolein triggers cell membrane scrambling at least in part by increasing the formation of ceramide, which in turn increases the $\mathrm{Ca}^{2+}$ sensitivity of cell membrane scrambling. Ceramide was known to stimulate apoptosis of nucleated cells ${ }^{[33]}$.

Emadi et al. ${ }^{[34]}$ reported leucopenia, thrombocytopenia, and anemia are common after high dose cyclophosphamide administration. A case of cyclophosphamide-induced methemoglobinemia has also been reported by Shehadeh et al. ${ }^{[35]}$ erythropoiesis failure, destruction of mature cells or increased plasma volume were some common causes of erythrocytopenia and decrease hematocrit values.

In mice CPA treatment for 12 weeks, mean values of $\mathrm{PCV}, \mathrm{MCV}, \mathrm{MCH}$ and $\mathrm{MCHC}$ values were significantly decreased as compared to the control group. Following the treatment with CPA decreased $\mathrm{MCV}, \mathrm{MCH}$ and reduced $\mathrm{MCHC}$ values suggest that microcytic hypochromic anemia was developed due to the suppression of erythropoiesis ${ }^{[36]}$. It was reported that ROS increases hemoglobin glycation and erythrocyte fragility and bone marrow can be damaged by direct oxidation ${ }^{[37]}$.

Thus, in the present study, it was observed that the decrease in all hematological indices after exposure to CPA was attributed to the production of erythrocytes with lower $\mathrm{MCV}, \mathrm{MCH}$ and $\mathrm{MCHC}$ and these parameters closely related to $\mathrm{Hb}$. $\mathrm{Hb}$ data could be strongly influenced by $\mathrm{MCV}, \mathrm{MCH}$ and $\mathrm{MCHC}$ values ${ }^{[38]}$.

The purpose of chemotherapy should not only to effectively remove tumor cells but also reduced the related immunosuppressive complications that are primarily caused by apoptosis of circulating leukocytes cells (leucopenia). Mice response to CPA chemotherapy caused severe immunosuppressive conditions, as reflected in a lower WBC count.

In the present study, it was observed that after royal jelly treatment the total leukocyte count, total erythrocyte count, hemoglobin \% $(\mathrm{Hb})$, thrombocyte count and the mean values of PCV, MCV, MCH and $\mathrm{MCHC}$ of experimental mice were significantly increased as compared to the control group.

Antioxidants can prevent cell damage caused by the action of ROS and free radicals ${ }^{[39]}$. The antioxidant activities were related to a number of different mechanisms, such as free radical scavenging, hydrogendonation, singlet oxygen quenching, metal ion chelation, and acting as a substrate for radicals such as superoxide and hydroxyl It had been publicized that immunemodulatory compounds along with chemotherapy may reduce myelosuppression and enhance the immune response. Recently, royal jelly had received particular attention as a highly effective antioxidant and has the free radical scavenging capacity ${ }^{[40]}$. It contains many important compounds with biological activity such as free amino acids, proteins, sugars, fatty acids, minerals, and vitamins ${ }^{[41]}$.

In the present study it was observed that after combined treatment of cyclophosphamide along with different concentration $100 \mathrm{mg} / \mathrm{kg} / \mathrm{d}$ (low dose), $250 \mathrm{mg} / \mathrm{kg} / \mathrm{d}$ (medium dose) and $500 \mathrm{mg} / \mathrm{kg} /$ day (high dose) of royal jelly (G4-G6), the total leukocyte count, total erythrocyte count, hemoglobin \% $(\mathrm{Hb})$, thrombocyte count and the mean values of PCV, MCV, $\mathrm{MCH}$ and $\mathrm{MCHC}$ of experimental mice were significantly increased as compared to animal treated with cyclophosphamide (G3).

In the current experiment, a significant increase of the erythrocyte counts in the RJ-treated groups indicated that RJ may have a stimulatory action on the erythrocytes synthesis and proliferation in the bone marrow. Our findings were harmonious with that reported by El-Tarabany ${ }^{[42]}$. Royal jelly had a protective role against many drugs ${ }^{[43]}$.

It is a rich source of antioxidants that opposed to myelosuppressive effects induced by CPA. The mechanism might be related to the recovery of hematopoiesis by means of modulating the bone marrow activity, as well as enhanced immune functions. RJ acts as an immune stimulator presumably due to its ability to alter the normal immune cell proliferation thus allowing efficient mobilization of an immune response.

Simsek et al. ${ }^{[44]}$ reported in their study on rats that an oral RJ application of $300 \mathrm{mg} \mathrm{kg}^{-1}$ day $^{-1}$ increases the number of erythrocytes and their diameters; therefore, it could be used as a supportive antioxidant molecule in anemic patients. Royal jelly was found to increase the 
number and diameters of erythrocytes; therefore, it could be used as a supportive antioxidant molecule in anemic patients. MRJPs stimulate cell proliferation by acting as bio-similar or substitutes for growth factors ${ }^{[45]}$. The royal jelly had a hemato-curative role against azathioprine ${ }^{[46]}$. Kanbur et al. ${ }^{[47]}$ revealed that royal jelly at a dose of $50 \mathrm{mg} / \mathrm{kg} / \mathrm{d}$ administration to mice ameliorates the oxidative stress in erythrocytes induced by fluoride. Administration of royal jelly to mice ameliorated the effect of radiation that induced oxidative stress and hematological alterations ${ }^{[48]}$.

The present study shown that the improvement in the tested blood parameters as erythrocytes, hemoglobin, leukocytes, platelets and the mean value of packed cell volume (PCV), mean corpuscular volume (MCV) and mean corpuscular hemoglobin $(\mathrm{MCH})$, mean corpuscular hemoglobin concentration ( $\mathrm{MCHC}$ ) indicates that royal jelly administration prevented blood cell damage by maintaining the integrity of cells.

\section{CONCLUSIONS}

Cyclophosphamide caused leucopenia, erythrocytopenia, thrombocytopenia and a significant decrease in $\mathrm{Hb} \%$ and mean values of $\mathrm{PCV}, \mathrm{MCV}, \mathrm{MCH}$, and $\mathrm{MCHC}$ while royal jelly was significantly improved and normalized all hematological parameters altered during cyclophosphamide treatment. These consequences were of clinical importance particularly, use of Royal jelly as an exclusive treatment or in combination to neutralizes cyclophosphamide side effects in cancer.

Further investigations on hem protective effect of royal jelly on cancerous animals would provide a supportive approach for the usage of royal jelly in the reduction of complications of chemotherapy.

\section{ACKNOWLEDGMENTS}

The authors gratefully acknowledge the University Grant Commission, New Delhi Govt. of India for financial support and the Principal of the Y. B. Chavan College of Pharmacy, Aurangabad, India, for providing all the necessary facilities.

\section{CONTRIBUTION OF AUTHORS}

Research concept- Syeda Hina Kausar

Research design- Syeda Hina Kausar

Supervision-Dr. Vitthal Ram More

Materials- Syeda Hina Kausar

Data collection- Syeda Hina Kausar

Data analysis and Interpretation- Syeda Hina Kausar
Literature search- Syeda Hina Kausar

Writing article- Syeda Hina Kausar

Critical review- Dr. Vitthal Ram More

Article editing- Syeda Hina Kausar

Final approval- Dr. Vitthal Ram More

\section{REFERENCES}

[1] Pass GJ, Carrie D, Boylan M, Lorimore S, Wright E, et al. Role of hepatic enzyme P450 in the pharmacokinetics and toxicity of cyclophosphamide: studies with the hepatic cytochrome p450 reductase null mouse. Cancer Res., 2005; 65: 4211-17.

[2] Rang HP, Dale MM, Ritter JM, Flower RJ, Henderson G. Rang and Dale's pharmacology. $8^{\text {th }}$ ed., Philadelphia: Elsevier, 2012; pp.750-60.

[3] Basu A, Bhattacharjee A, Somnath SR, Ghosh P, Chakraborty $P$, et al. (Vanadium as a chemoprotectant: effect of vanadium (III)-L-cysteine complex against cyclophosphamide- induced hepatotoxicity and genotoxicity in Swiss albino mice. J. Biol. Inorg. Chem., 2014; 19(6): 981-96.

[4] Ghosh P, Bhattacharjee A, Basu A, Roy S, Bhattacharya S. Attenuation of cyclophosphamideinduced pulmonary toxicity in Swiss albino mice by naphthalimide-based organoselenium compound 2-(5-selenocyanatopentyl)-benzo[de]isoquinoline 1 , 3-dione. Pharm. Biol., 2015; 53: 524-32.

[5] Lu WP, Mei XT, Wang Y, Zheng YP, Xue YF, et al. Zn (II)-curcumin protects against oxidative stress, deleterious changes in sperm parameters and histological alterations in a male mouse model of cyclophosphamide-induced reproductive damage. Environ. Toxicol. Pharmacol., 2015; 39: 515-24.

[6] Sun $H X$, Peng XY. Protective effect of triterpenoid fractions from the rhizomes of astilbechinensis on cyclophosphamide-induced toxicity in tumor bearing mice. J. Ethnopharmacol., 2008; 119: 312-17.

[7] Bhattacharjee A, Basu A, Biswas J, Bhattacharya S. Nano-Se attenuates cyclophosphamide- induced pulmonary injury through modulation of oxidative stress and DNA damage in Swiss albino mice. Mol. Cell. Biochem., 2015; 405: 243-56.

[8] Nafees S, Rashid S, Ali N, Hasan SK, Sultana S. Rutin ameliorates cyclophosphamide induced oxidative stress and inflammation in Wistar rats: role of NFKB/MAPK pathway. Chem. Biol. Interact., 2015; 231: 98-107. 
[9] Selvakumar E, Prahalathan C, Sudharsan PT, Varalakshmi P. Chemoprotective effect of lipoic acid against cyclophosphamide induced changes in the rat sperm. Toxico., 2006; 217(1): 71-78.

[10]Bhattacharjee A, Basu A, Ghosh P, Biswas J, Bhattacharya S. Protective effect of Selenium nanoparticle against cyclophosphamide induced hepatotoxicity and genotoxicity in Swiss albino mice.

J. Biomater. Appl., 2014; 29: 303-17.

[11]Isidorov VA, Czyzewska U, Isidorova AG, Bakier S. Gas chromatographic and mass spectrometric characterization of the organic acids extracted from some preparations containing lyophilized Royal jelly.

J. Chromatogr., 2009; 877: 3776-80.

[12]Stocker A, Schramel P, Kettrup A, Bengsch E. Trace and mineral elements in Royal jellyand homeostatic effects. J. Trace Elem. Med. Biol., 2005; 19(2-3): 183-89.

[13]Nagai T, Inoue R. Preparation and the functional properties of water extract and alkaline extract of Royal jelly. Food Chem., 2004; 84(2): 181-86.

[14]Inoue S, Koya-Miyata S, Ushio S, Iwaki K, Ikeda M, et al. Royal jellyprolongs the life span of $\mathrm{C} 3 \mathrm{H} / \mathrm{HeJ}$ mice: correlation with reduced DNA damage. Exp. Gerontol., 2003; 38(9): 965-69.

[15]El-aidy WK, Ebeid AA, Sallam AEM, Muhammad IE, Abbas AT, et al. Evaluation of propolis, honey, and Royal jelly in amelioration of peripheral blood leukocytes and lung inflammation in mouse conalbumin-induced asthma model. Saudi J. Biol. Sci., 2015; 22(6): 780-88.

[16]Silici S, Ekmekcioglu O, Eraslan G, Demirtas A. Antioxidative effect of Royal jelly in cisplatin-induced testes damage. Urol., 2009; 74(3): 545-51.

[17]United States Pharmacopeial Convention. The United States Pharmacopeia-NationalFormularyRockville: United States Pharmacopeia; 2011: 1416-19.

[18]Pratheeshkumar P, Kuttan G. Ameliorative action of Vernoniacinerea $L$. on cyclophosphamide-induced immunosuppression and oxidative stress in mice. Inflammopharmacology, 2010; 18(4): 197-207.

[19]Yoshida M, Tomitori H, Machi Y, Hagihara M, Higashi $\mathrm{K}$, et al. Acrolein toxicity: comparison with reactive oxygen species. Biochem. Bio. Phys. Res. Commun., 2009; 378 (2): 313-18.

[20]Elshater AA, Haridy MA, Salman MMA, Fayyad AS, Hammad S. Fullerene $C 60$ nanoparticles ameliorated cyclophosphamide-induced acute hepatotoxicity in rats. Biomed. Pharmacother., 2018; 97: 53-59.

[21]Bhattacharjee A, Basu A, Biswas J, Sen T, Bhattacharya S. Chemoprotective and chemosensitizing properties of selenium nanoparticle ( Nano-Se ) during adjuvant therapy with cyclophosphamide in tumor-bearing mice. Mol. Cell. Biochem., 2017; 424 (1-2): 13-33.

[22] Duggina P, Kalla CM, Varikasuvu SR, Bukke S, Tatte V. Protective effect of centella triterpene saponins against cyclophosphamide-induced immune and hepatic system dysfunction in rats: Its possible mechanisms of action. J. Physiol. Bio. chem., 2015; 71 (3): 435-54.

[23]Mazur L, Czyzewska A, Bochenek M. Flow cytometric detection of apoptotic bone marrow cells with fractional DNA content after application of WR-2721, cyclophosphamide, cisplatin, and exposure of mice to gamma rays. Hum. Exp. Toxicol., 2002; 21: 335-41.

[24]Shalit I, Kletter Y, Halperin D, Waldman D, Vasserman $E$, et al. Immunomodulatory effects of moxifloxacin in comparison to ciprofloxacin and G-CSF in a murine model of cyclophosphamide induced leukopenia Eur. J. Haematol., 2001; 66: 287-296.

[25]De Weerdt O, Van de Donk NW, Veth G, Bloem AC, Hagenbeek $A$, et al. Continuous low-dose cyclophosphamide-prednisone is effective and well tolerated in patients with advanced multiple myeloma. Neth. J. Med., 2001; 59: 50-56.

[26]Fraiser LH, Kanekal S, Kehrer JP. Cyclophosphamide toxicity. Drugs, 1991; 42: 781-95.

[27]Patra K, Bose S, Sarkar S, Rakshit J, Jana S, Mukherjee $A$, et al. Amelioration of cyclophosphamide induced myelosuppression and oxidative stress by cinnamic acid. Chem. Biol. Interact., 2012; 195: 231-39.

[28]Feng L, Huang Q, Huang Z, Li H, Qi X, et al. Optimized Animal Model of Cyclophosphamide-induced Bone Marrow Suppression. Basic Clin. Pharmacol. Toxicol., 2016; 119(5): 428-35.

[29]Langford C. Complications of cyclophosphamide therapy. Eur. Arch. Otorhinolaryngol., 1997; 254 (2): 65-72.

[30]Ahmed MS, Langer H, Abed M, Voelkl J, Lang F. The Uremic Toxin Acrolein Promotes Suicidal Erythrocyte Death. Kidney Blood Press Res., 2013; 37: 158-67. 
[31]Lang E, Qadri SM, Lang F. killing me softly-suicidal erythrocyte death. Int. J. Biochem. Cell Biol. 2012; 44: 1236-43.

[32] Lang PA, Kaiser S, Myssina S, Wieder T, Lang F, et al. Role of $\mathrm{Ca}^{2+}$-activated $\mathrm{K}+$ channels in human erythrocyte apoptosis. Am. J. Physiol. Cell Physiol., 2003; 285: 1553-60.

[33]Morad SA, Cabot MC. Ceramide-orchestrated signaling in cancer cells. Nat. Rev. Cancer, 2013; 13: 51-65.

[34]Emadi A, Jones RJ, Brodsky RA. Cyclophosphamide and cancer: golden anniversary. Nat. Rev. Clin. Oncol., 2009; 6: 638-47.

[35]Shehadeh N, Dansey R, Seen S, Abella E. Cyclophosphamide-induced methemoglobinemia. Bone Marrow Transplant, 2003; 32: 1109-10.

[36] Gao LP, Li Z, Guo ZY, Zhao YM. The effects of vitamin $C$ on DDP induced anemia in rats. Toxicol. Mech. Methods., 2013; 23: 383-88.

[37]Niforou K, Cheimonidou C, Trougakos IP. Molecular chaperones and proteostasis regulation during redox imbalance. Redox. Biol., 2014; 2: 323-32.

[38]Bosing B, Tunsmeyer J, Mischke R, Beyerbach $M$, Kastner SB. Clinical usability and practicability of Alfaxalone for short-term anesthesia in the cat after premedication with Buprenorphine. Tierarztl. Prax. Ausg. K. Kleintiere. Heimtiere., 2012; 40: 17-25.

[39]Cherubini A, Vigna GB, Zuliani G. Role of antioxidant satherosclerosis: an epidemiological and clinical update. Curr. Pharm. Des., 2005; 11: 2017-32.

[40]Seyyedi F, Rafiean-Kopaei M, Miraj S. Comparison of the effects of vaginal royal jelly and vaginal estrogen on quality of life, sexual and urinary function in postmenopausal women. J. Clin. Diagn. Res., 2016; 10: QC01.
[41]Nakajima Y, Tsuruma K, Shimazawa M, Mishima S, Hara $\mathrm{H}$. Comparison of bee products based on assays of antioxidantcapacities. BMC Complementary Altern. Med., 2009; 8: 04-09.

[42]El-Tarabany MS. Effect of Royal Jelly on behavioural patterns, feather quality,egg quality and some haematological parameters in laying hensat the late stage of production. J. Anim. Physiol. Anim. Nutr., 2017; 01-08.

[43]Malekinejad $H$, Ahsan S, Delkhosh F, Cheraghi $H$, Golmisheh A, et al. Cardioprotective effect of royal jelly on paclitaxel-induced cardio-toxicity in rats. Iran J. Basic Med. Sci., 2016; 19(2): 221-27.

[44]Simsek N, Karadeniz A, Bayraktaroglu AG. Effects of L-carnitie, royal jelly and pomegranate seed on peripheral blood cells in rats. Kafk as Univ. Vet. Fak. Derg., 2009; 15: 63-69.

[45]Kamakura M, Suenobu N, Fukushima M. Fifty-seven kDa protein in royal jelly enhances proliferation of primary cultured rat hepatocytes and increases albumin production in the absence of serum. Biochem. Biophys. Res. Commun., 2001; 282: 865-74

[46]Ahmeda WM, Khalaf AA, Moselhyc WA, Safwat GM. Royal jelly attenuates azathioprine-induced toxicity in rats. Environ. Toxicol. Pharmacol., 2014; 37: 431-37.

[47]Kanbur M, Eraslan G, Silici S, Karabacak M. Effects of sodium fluoride exposure on some biochemical parameters in mice: Evaluation of the ameliorative effect of royal jelly applications on these parameters. Food and Chemical Toxicology, 2009; 47(6): 1184-89.

[48]Azab KS, Bashandy M, Salem M, Ahmed O, Tawfik Z, et al. Royal jelly modulates oxidative stress and tissue injury in gamma-irradiated male Wister albino rats. N. Am. J. Med. Sci. 2011; 3: 268-76. 